\title{
Upregulation of fractalkine contributes to the proliferative response of prostate cancer cells to hypoxia via promoting the $G_{1} / S$ phase transition
}

\author{
JIEBING TANG ${ }^{1,2^{*}}$, YUANYUAN CHEN $^{1 *}$, RONGJUN CUI $^{3}$, DONG LI $^{1}$, LIJIE XIAO $^{1}$, \\ PING LIN ${ }^{1}$, YANDAN DU ${ }^{4}$, HUI SUN ${ }^{1,4}$, XIAOGUANG YU ${ }^{1}$ and XIULAN ZHENG ${ }^{5}$ \\ ${ }^{1}$ Department of Biochemistry and Molecular Biology, Harbin Medical University; \\ ${ }^{2}$ Department of Gastrointestinal Medical Oncology, The Affiliated Tumor Hospital of Harbin Medical University, \\ Harbin, Heilongjiang 150081; ${ }^{3}$ Department of Biochemistry and Molecular Biology, \\ Mudanjiang Medical University, Mudanjiang, Heilongjiang 157011; ${ }^{4}$ Department of Clinical Laboratory, \\ The Second Clinical Medical School of Inner Mongolia University for the Nationalities, \\ Inner Mongolia Forestry General Hospital, Hulunbuir, Inner Mongolia 022150; \\ ${ }^{5}$ Department of Ultrasonography, The Affiliated Tumor Hospital of Harbin Medical University, \\ Harbin, Heilongjiang 150081, P.R. China
}

Received December 3, 2014; Accepted August 25, 2015

DOI: $10.3892 / \mathrm{mmr} .2015 .4438$

\begin{abstract}
Hypoxia is a common phenomenon in prostate cancer, which leads to cell proliferation and tumor growth. Fractalkine (FKN) is a membrane-bound chemokine, which is implicated in the progression of human prostate cancer and skeletal metastasis. However, the association between FKN and hypoxia-induced prostate cancer cell proliferation remains to be elucidated. The present study demonstrated that hypoxia induced the expression and secretion of FKN in the DU145 prostate cancer cell line. Furthermore, inhibiting the activity of FKN with the anti-FKN FKN-specific antibody markedly inhibited hypoxia-induced DU145 cell proliferation. Under normoxic conditions, DU145 cell proliferation markedly
\end{abstract}

Correspondence to: Dr Xiaoguang Yu, Department of Biochemistry and Molecular Biology, Harbin Medical University, 194 Xuefu Road, Harbin, Heilongjiang 150081, P.R. China

E-mail: xiaoguang_yu@hotmail.com

Dr Xiulan Zheng, Department of Ultrasonography, The Affiliated Tumor Hospital of Harbin Medical University, 150 Haping Road Harbin, Heilongjiang 150081, P.R. China

E-mail: zx12496@163.com

*Contributed equally

Abbreviations: CCK-8, cell counting kit-8; CDKs, cyclin-dependent kinases; EGFR, epidermal growth factor receptor; FBS, fetal bovine serum; FKN, fractalkine; NK, natural killer; RT-qPCR reverse transcription-quantitative polymerase chain reaction

Key words: cell cycle, DU145 cells, fractalkine, hypoxia, proliferation increased following exogenous administration of human recombinant FKN protein, and the increase was significantly alleviated by anti-FKN, indicating the importance of FKN in DU145 cell proliferation. In addition, subsequent determination of cell cycle distribution and expression levels of two core cell cycle regulators, cyclin $\mathrm{E}$ and cyclin-dependent kinase (CDK)2, suggested that FKN promoted the $\mathrm{G}_{1} / \mathrm{S}$ phase transition by upregulating the expression levels of cyclin $\mathrm{E}$ and CDK2. The results of the present study demonstrated that hypoxia led to the upregulation of the secretion and expression of FKN, which enhanced cell proliferation by promoting cell cycle progression in the prostate cancer cells. These findings provide evidence of a novel function for FKN, and suggest that FKN may serve as a potential target for treating androgen-independent prostate cancer.

\section{Introduction}

Prostate cancer is one of the most common types of non-cutaneous malignancy in males. In the United States, the incidence of prostate cancer is highest among male malignant tumors (1). In China, increasing evidence suggests that the age of onset of prostate cancer has been decreasing in recent years (2). Although early-stage prostate cancer can be cured by radical prostatectomy, for patients with clinically detectable metastasis, there remains a lack of effective treatment options (3).

Intratumoral hypoxia prevails in several types of fast growing solid tumor and is a marker of poor clinical prognosis in prostate cancer (4). The reaction of tumor cells to hypoxia includes the generation of signal transducing molecules, predominantly growth factors and cytokines, and changes in tumor cell function, which affect cell proliferation, de-differentiation, resistance to apoptosis and metastatic potential (5). 
Chemokines are small, chemoattractant proteins, which have the ability to chemoattract cells expressing their cognate $\mathrm{G}$ protein-coupled receptors. On the basis of structure, chemokines are divided into four subfamilies: CXC, CC, C and CX3C (6). Several studies have suggested that chemokines and their receptors are involved in a number of disease states, including cardiovascular disease (7), systemic inflammation (8), cancer (9) and infectious disorders (10). Fractalkine (FKN, also known as CX3CL1), is a unique chemokine subclass and the only member of the $\mathrm{CX} 3 \mathrm{C}$ chemokine family, existing as a membrane-bound form and a soluble form. The membrane-bound form is synthesized as a transmembrane molecule with an extracellular N-terminal domain attached by a mucin-like stalk to the cell surface (6). Soluble FKN is generated via cleavage at the base of the mucin-like stalk by the metalloproteinases, A disintegrin and metalloproteinase 10 and 17 (11). Several studies have identified that FKN is expressed by a variety of tumors, including prostate cancer, and there has been increasing interest in its involvement in prostate cancer (12-15). FKN-CX3CR1 is reported to be involved in the molecular events that regulate the adhesion, migration and survival of human prostate cancer cells (15). In addition, FKN-CX3CR1 binding has also been observed to be crucial in the progression of prostate cancer and skeletal metastasis (12).

Hypoxia leads to tumor cell proliferation and tumor growth. Emerging evidence has indicated that hypoxia can promote tumor growth by upregulating specific chemokine receptors, including CCR2 (16). Our previous study demonstrated that hypoxia increases the expression of CX3CR1 via the hypoxia-inducible factor and nuclear factor- $\mathrm{\kappa B}$ signaling pathway in androgen-independent prostate cancer cells (17). However, the association between FKN and hypoxia-induced prostate cancer cell proliferation remains to be fully elucidated.

The present study aimed to determine the effect of a hypoxic microenvironment on the expression of FKN and the role of FKN in hypoxia-induced prostate cancer cell proliferation. The results showed that FKN expression was upregulated under hypoxic conditions, which resulted in enhanced proliferation of prostate cancer cells.

\section{Materials and methods}

Cell lines and reagents. DU145 and PC-3 human prostate cancer cell lines were purchased from American Type Culture Collection (Manassas, VA, USA). Human recombinant FKN was purchased from R\&D systems, Inc. (Minneapolis, MN, USA). Anti-human FKN antibody was purchased from Abcam (Cambridge, MA, USA). CDK2 primary antibody [mouse monoclonal immunoglobulin (Ig)G; cat no. sc-6248] was obtained from Santa Cruz Biotechnology Inc. (Dallas, TX, USA) and cyclin E primary antibody (rabbit monoclonal IgG; cat no. 2978s) was purchased from Cell Signaling Technology Inc. (Danvers, MA, USA). The secondary antibodies for CDK2 (anti-mouse IgG; cat no. A16027) and cyclin E (anti-rabbit IgG; cat no. A16104) were from Invitrogen (Thermo Fisher Scientific, Inc., Waltham, MA, USA). All primers used in the present study were synthesized by Sangon Biotech Co., Ltd (Shanghai, China).

Cell culture and hypoxia exposure. Under normoxic conditions the cells were maintained in RPMI-1640 medium containing
$10 \%$ fetal bovine serum (Gibco Life Technologies, Carlsbad, CA, USA) and $1 \mathrm{X}$ penicillin/streptomycin (Invitrogen Life Technologies, Carlsbad, CA, USA) at $37^{\circ} \mathrm{C}$ in a humidified atmosphere containing $5 \% \mathrm{CO}_{2}$ and $95 \%$ air. The cells that were grown under hypoxic conditions were incubated in a hypoxic chamber (Thermo Fisher Scientific, Inc.) containing $1 \% \mathrm{O}_{2}$, $5 \% \mathrm{CO}_{2}$ and $94 \% \mathrm{~N}_{2}$ at $37^{\circ} \mathrm{C}$.

Cell proliferation assay. The cells were seeded at a density of $3 \times 10^{3}$ cells/well into a 96 -well plate. Cell proliferation was measured following 12, 24, 36, 48 and $72 \mathrm{~h}$ of normoxic or hypoxic culture using a Cell Counting kit-8 (CCK-8; Dojindo Molecular Technologies, Inc., Kumamoto, Japan), according to the manufacturer's instructions. Briefly, CCK- 8 reagents were added to a subset of wells and incubated for $2 \mathrm{~h}$ at $37^{\circ} \mathrm{C}$, following which the absorbance was measured at a test wave length of $450 \mathrm{~nm}$ on an automated plate reader (SpectraMax M3; Molecular Devices, Sunnyvale, CA, USA).

Colony formation assay. The cells were seeded into a 6-well plate at a density of 200 cells/well and incubated for 10 days to allow colony formation. The colonies were fixed with $3 \%$ formaldehyde (Tianjin Fuyu Fine Chemical Co., Ltd., Tianjin, China) and stained with $0.1 \%$ crystal violet (Shanghai Bogoo Biotechnology Co., Ltd., Shanghai, China). The number of colonies containing $>50$ cells were counted. The colonies were manually counted using a microscope (Olympus TH4-200; Olympus, Tokyo, Japan) and images of the colonies were captured.

Flow cytometric analysis of cell cycle. Cell cycle analysis was performed using flow cytometry. DU145 cells were pre-incubated with FKN, with $200 \mathrm{pg} / \mathrm{ml}$ human recombinant FKN protein added to the medium when the cells were $80 \%$ confluent. The cells were harvested and fixed with $70 \%$ ethanol prior to being stored at $4^{\circ} \mathrm{C}$ overnight. The fixed cells were incubated with RNase $(25 \mu \mathrm{g} / \mathrm{ml}$; Sigma-Aldrich, St Louis, $\mathrm{MO}, \mathrm{USA}$ ) at $37^{\circ} \mathrm{C}$ for $30 \mathrm{~min}$, and the DNA was subsequently stained with propidium iodide (50 $\mu \mathrm{g} / \mathrm{ml}$; Sigma-Aldrich) for $30 \mathrm{~min}$ in the dark. The stained cells were then analyzed by fluorescence-activated cell sorting using a FACSCalibur flow cytometer (BD Biosciences, San Jose, CA, USA).

Reverse transcription-quantitative polymerase chain reaction $(R T-q P C R)$. Total RNA was extracted from the cells incubated under normoxic or hypoxic conditions using TRIzol ${ }^{\circledR}$ reagent (Invitrogen Life Technologies). RNA was reverse transcribed into cDNA using Superscript II Reverse Transcriptase (Invitrogen Life Technologies), according to the manufacturer's instructions. The cDNA ( $1 \mu \mathrm{g}$ in $4 \mu \mathrm{l}$ buffer) was amplified by qPCR in an ABI 7500 real-time PCR system (Applied Biosystems; Thermo Fisher Scientific) using the SYBR Select Master Mix kit (Applied Biosystems) and with gene-specific primers $(1 \mu \mathrm{l})$. The primers used in the present study were as follows: $\beta$-actin sense, 5'-TACCTCATGAAGATCCTCACC-3' and antisense, 5'-TTTCGTGGATGCCACAGGAC-3'; CDK2 sense, 5'-CAGGATGTGACCAAGCCAGTA-3' and antisense, 5'-CCAACCCTCTCCAGCAATAA-3'; cyclin E sense, 5'-ACGACGACGACGAAAAACTC-3' and antisense, 5'-GTTGCGACGCTGAAGAGAAC-3'; and FKN sense, 
5'-CTTTCTCATCCACTATCAACA-3'; and antisense, 5'-CTCCACTACTCTTTC-3'. All the primers were purchased from Sangon Biotech Co. Ltd. The thermocycling conditions were initial denaturation at $94^{\circ} \mathrm{C}$ for $2 \mathrm{~min}$, followed by 30 cycles of $98^{\circ} \mathrm{C}$ for $10 \mathrm{sec}, 60^{\circ} \mathrm{C}$ for $15 \mathrm{sec}$ and $68^{\circ} \mathrm{C}$ for $2 \mathrm{~min}$. Each reaction was repeated in triplicate to minimize experimental variation, and the expression levels of $\beta$-actin were used as an internal control. The results were quantitated by scanning densitometry using a Bio-Rad 620 Video Densitometer (BioRad Laboratories, Hercules, CA, USA)

Western blot analysis. The total protein of cyclin E and CDK2 were extracted prior to western blot analysis. Western blot analysis was performed, as described previously (18). Briefly, the cells were washed with PBS and re-suspended in cold lysis buffer with phenylmethanesulfonylfluoride. The cell lysate was incubated on ice for $30 \mathrm{~min}$ and centrifuged at $12,000 \mathrm{x}$ g for $15 \mathrm{~min}$ at $4^{\circ} \mathrm{C}$.The protein concentration of the lysate was determined using a BCA-200 protein assay kit (Beyotime Institute of Biotechnology, Inc., Haimen, China). Equal quantities of protein (40 $\mu \mathrm{g} / \mathrm{lane})$ were separated by $12 \%$ SDS-PAGE and transferred onto nitrocellulose membranes (Pall Corp., Port Washington, NY, USA). Following blocking with 5\% fat-free milk for $2 \mathrm{~h}$ at room temperature, the membranes were incubated with various primary antibodies (1:500) at $4^{\circ} \mathrm{C}$ overnight. Subsequently, the bound primary antibody was detected by incubating with appropriate horseradish peroxidase-conjugated secondary antibodies $(1: 1,000)$ for $2 \mathrm{~h}$ at room temperature, followed by washing with Tris-buffered saline containing Tween 20 three times. The immunoreactive bands were visualized using blot analysis Super ECL Plus Detection Reagents (Applygen Technologies Inc., Beijing, China). The volumes of the protein bands were quantified using a Bio-Rad Chemi Doc ${ }^{\mathrm{TM}} \mathrm{EQ}$ densitometer and Bio-Rad Quantity One software (Bio-Rad Laboratories). The expression levels of tubulin were assessed as an internal control.

ELISA assay. The concentration of soluble FKN in the supernatant was determined using an FKN ELISA kit (R\&D Systems, Inc., Minneapolis, MN, USA) following the manufacturer's instructions and in accordance with the procedure of a previous study (19).

Statistical analysis. The results of the present study are expressed as the mean \pm standard error of the mean. Each experiment was repeated in triplicate. One-way analysis of variance was used for multiple comparisons. Statistical analyses were performed using SAS software version 9.1.3 (SAS Institute Inc., Cary, NC, USA). Statistical differences between two groups were analyzed using an unpaired two tailed Student's $t$-tests. $\mathrm{P}<0.05$ was considered to indicate a statistically significant difference.

\section{Results}

Hypoxia induces prostate cancer cell proliferation. To examine the response of prostate cancer cell proliferation to hypoxia, two types of androgen-independent prostate cancer cell lines, DU145 and PC-3, were cultured under normoxic or hypoxic conditions, respectively. Firstly, cell viability was determined following 12, 24, 36, 48 and $72 \mathrm{~h}$ of culture using a CCK-8 assay. Morphological changes were also observed using an inverted microscope. DU145 and PC-3 cell proliferation was continuous under the hypoxic and normoxic conditions. The cell proliferation rates of the DU145 and PC-3 cells exposed to hypoxia were significantly higher, compared with those under normoxia at 24-48 h ( $\mathrm{P}<0.05$; Fig. $1 \mathrm{~A}$ and B). Furthermore, microscopic observation revealed markedly increased cell density in the two cell lines following $24 \mathrm{~h}$ culture under hypoxic conditions, compared with normoxic conditions, and cell growth under hypoxic and normoxic conditions remained normal as observed by inverted microscopy (Fig. 1C and D). Subsequently, the colony-forming ability of the DU145 and PC- 3 cells under the two conditions were determined in order to further confirm the effect of hypoxia on prostate cancer cell proliferation. The clone clusters of the two cell lines under hypoxic conditions were larger and more numerous, compared with those under normoxic conditions for 10 days (Fig. 2). The results suggested that hypoxia induced DU145 and PC-3 cell proliferation. In addition, the DU145 cell proliferative response to hypoxic treatment was more marked, compared with that of the PC-3 cells. Therefore, DU145 cells were selected as the experimental cells for subsequent investigation of the underlying molecular mechanisms.

Hypoxia upregulates the mRNA expression and secretion of $F K N$. To assess the effects of hypoxia on mRNA expression, the mRNA expression levels of FKN in DU145 cells was examined $0,6,12$ and $24 \mathrm{~h}$ following hypoxic treatment. RT-qPCR demonstrated that FKN was expressed at low levels in the DU145 cells. However, with increasing duration of hypoxic treatment, the mRNA expression of FKN increased in a time-dependent manner, with significant differences at 12 and $24 \mathrm{~h}(\mathrm{P}<0.05$; Fig. $3 \mathrm{~A}$ and $\mathrm{B})$, which resembled the response of cell proliferation to hypoxia. These results suggested that hypoxia-upregulated the mRNA expression of FNK in a time-dependent manner in the prostate cancer cells. In addition, the concentration levels of soluble FKN in the supernatant, determined using an ELISA kit, revealed that the protein secretion levels of FKN in the DU145 cells increased significantly following $24 \mathrm{~h}$ of hypoxic treatment, compared with those following normoxic treatment $(\mathrm{P}<0.05$; Fig. 3C). Therefore, the results suggested a positive correlation between FKN and hypoxic prostate cell proliferation.

Hypoxia-induced prostate cancer cell proliferation is mediated by FKN. To investigate the role of FKN in hypoxia-induced prostate cancer cell proliferation, FKN-specific antibody anti-FKN or isotype IgG were added to the hypoxic DU145 cells, and cell proliferation was determined following 24 and $48 \mathrm{~h}$ of incubation using a CCK-8. As shown in Fig. 4A, DU145 cell proliferation was markedly inhibited by anti-FKN pretreatment $(\mathrm{P}<0.05)$. To further verify the role of FKN in prostate cancer cell proliferation, the proliferation of the cells was also examined following exogenous administration of human recombinant FKN protein $(100 \mathrm{pg} / \mathrm{ml}$ or $200 \mathrm{pg} / \mathrm{ml})$ under normoxic conditions. As shown in Fig. 4B, DU145 cell proliferation was markedly enhanced by treatment with $200 \mathrm{pg} / \mathrm{ml}$ exogenous FKN protein $(\mathrm{P}<0.05)$, and this increase was significantly alleviated by anti-FKN $(\mathrm{P}<0.05)$. These data suggested that FKN was involved in the regulation of hypoxic prostate cancer cell proliferation. 

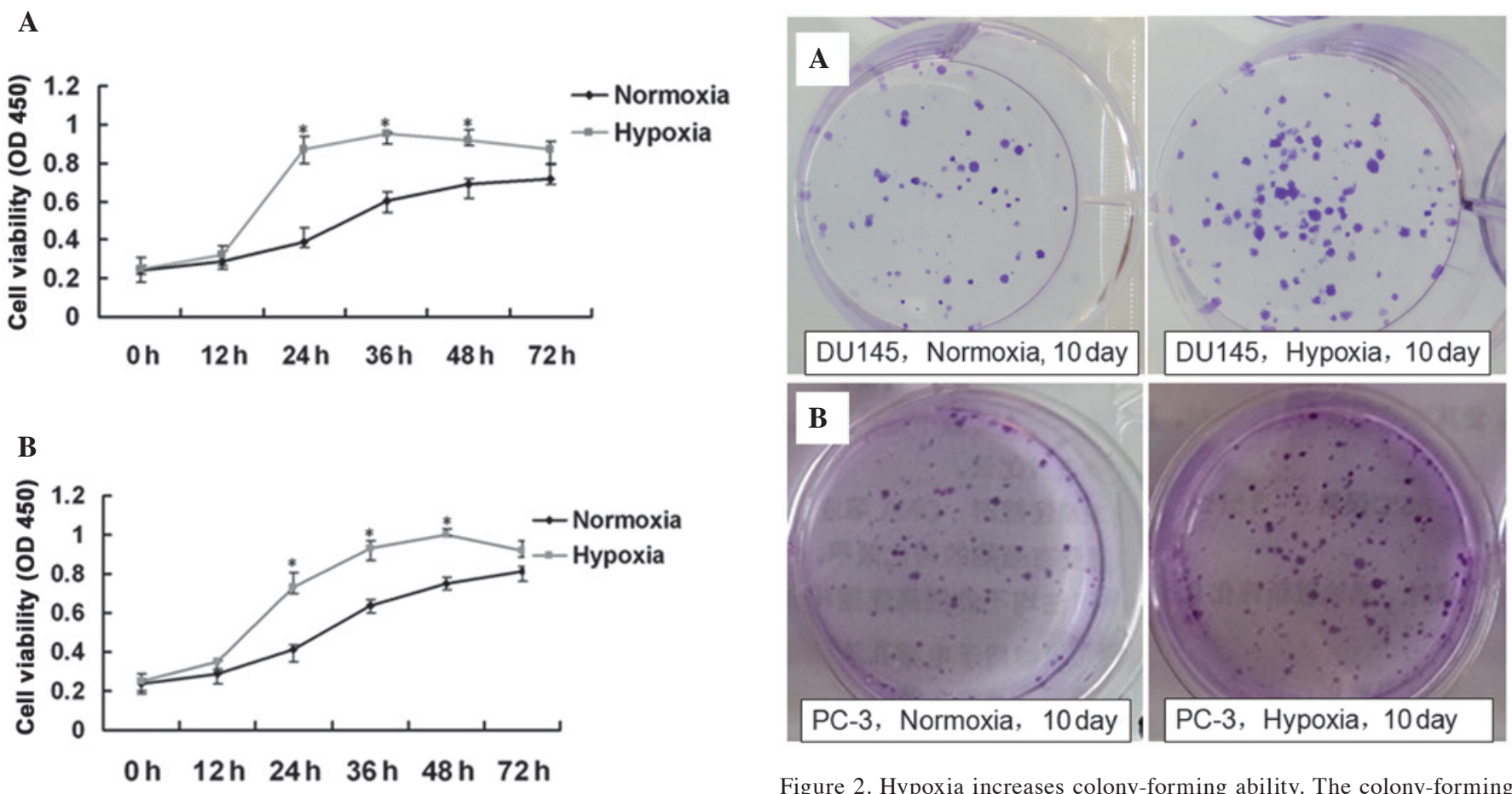

C

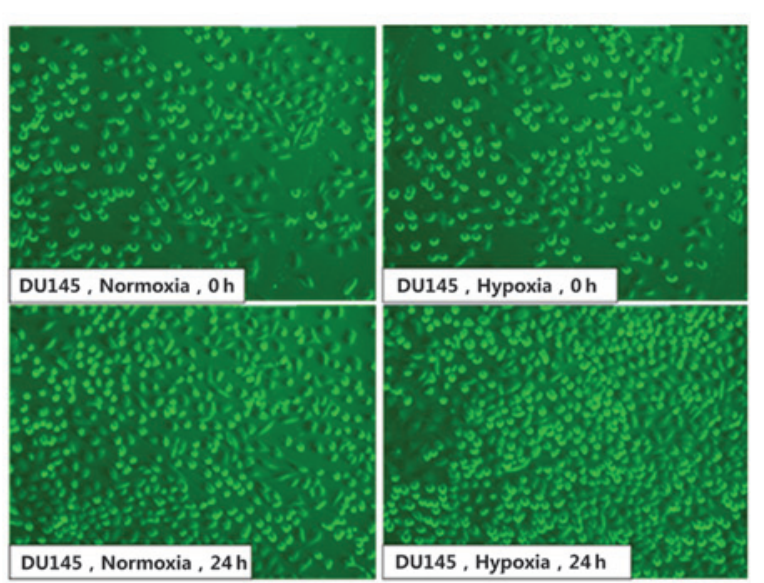

D

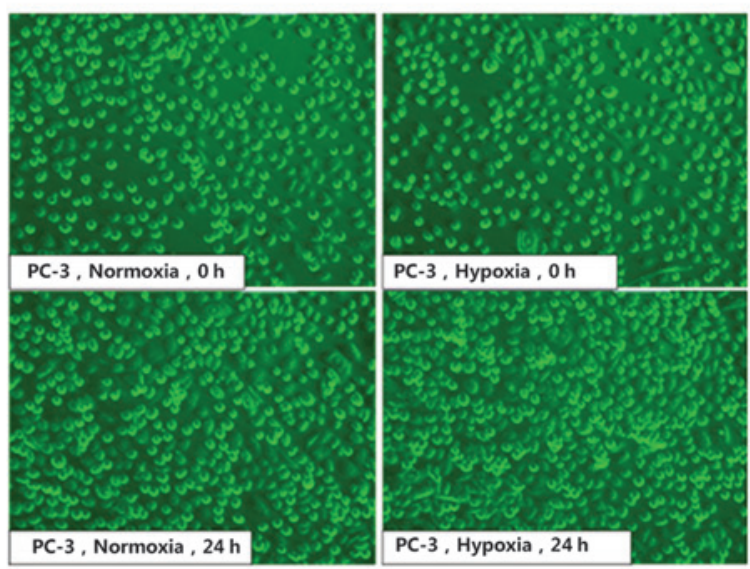

Figure 1. Hypoxia increases prostate cancer cell proliferation in androgen-independent prostate cancer cell lines. Proliferation of (A) DU145 and (B) PC-3 cells cultured in hypoxic and normoxic conditions for different durations were determined using a Cell Counting kit- 8 assay. Data are expressed as the mean \pm standard error of the mean. Microscopic observation of (C) DU145 and (D) PC-3 following $24 \mathrm{~h}$ of culture under hypoxic or normoxic conditions (magnification, $\mathrm{x} 100$ ). Cell density significantly increased in the two cell lines following $24 \mathrm{~h}$ of hypoxic culture, compared with normoxic culture. ${ }^{*} \mathrm{P}<0.05$, vs. normoxic conditions. OD, optical density.

Figure 2. Hypoxia increases colony-forming ability. The colony-forming ability of the (A) DU145 and (B) PC-3 cells (crystal violet stained) were determined using a colony formation assay. The cells were seeded into a six-well plate and incubated for 10 days to allow colony formation. The clone clusters of the two cell lines under hypoxic treatment were larger and more numerous, compared with those under normoxic treatment for 10 days.

A
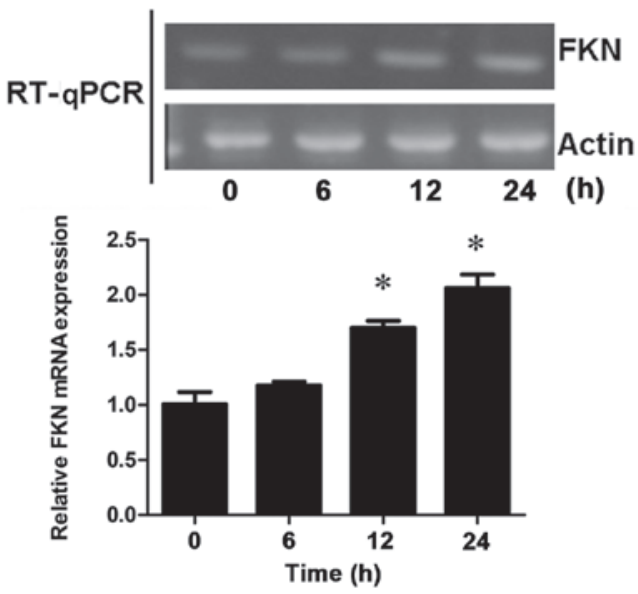

B

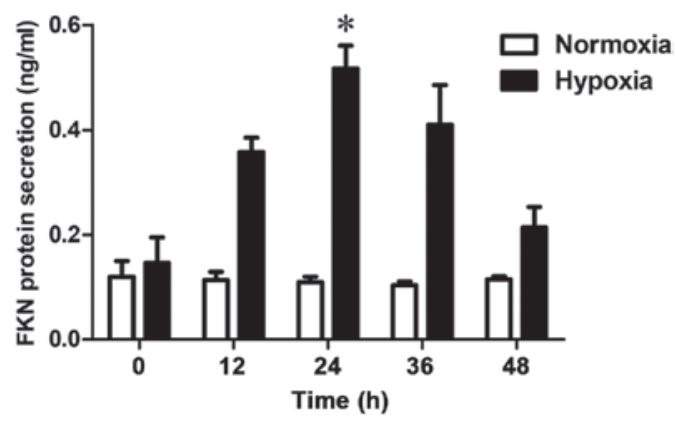

Figure 3. Hypoxia increases the mRNA expression and secretion of FKN in DU145 cells. (A) RT-qPCR analysis of the mRNA expression of FKN. The intensity of each band was quantified using densitometry, and data were normalized to those of actin. (B) ELISA analysis of the protein secretion of FKN in the supernatant. ${ }^{*} \mathrm{P}<0.05$, vs. $0 \mathrm{~h}$. Data are expressed as the mean \pm standard error of the mean. FKN, fractalkine; RT-qPCR, reverse transcription-quantitative polymerase chain reaction. 
A

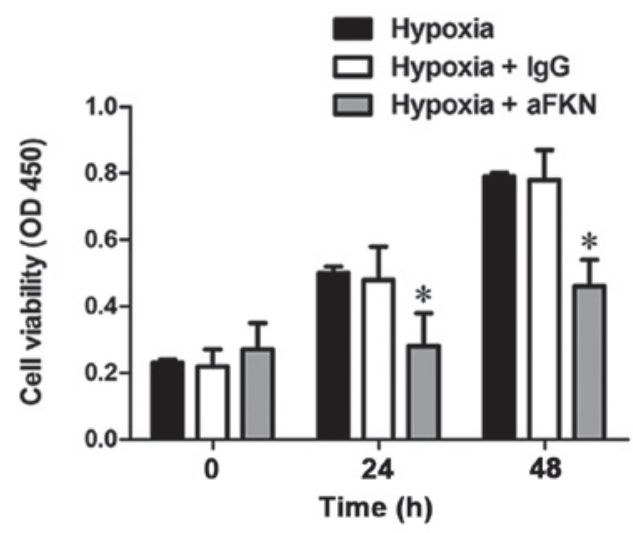

B
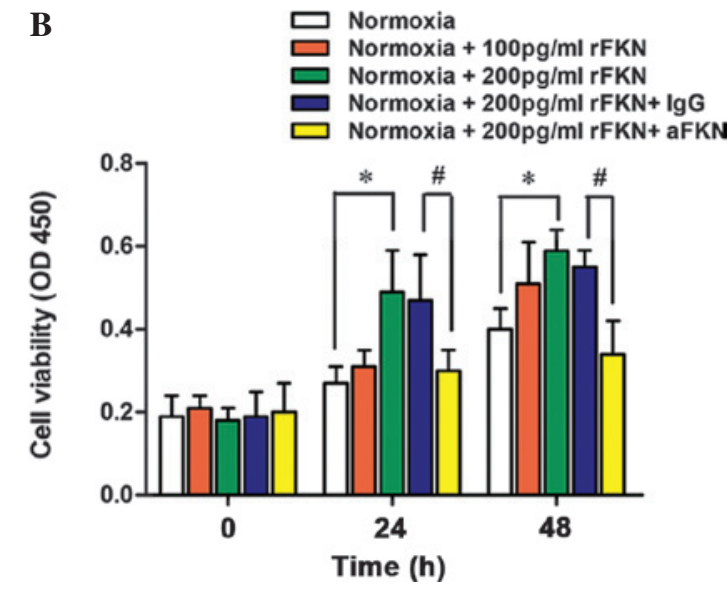

Figure 4.FKN in hypoxia-induced DU145 cell proliferation. (A) Antagonzing FKN significantly inhibited hypoxia-induced DU145 cell proliferation. ${ }^{*}$ P $<0.05$, vs . hypoxia + IgG. (B) Effect of FKN on DU145 cell proliferation in normoxic conditions. DU145 cell proliferation was markedly increased by 200 pg/ml exogenous FKN. This enhancement was significantly alleviated by anti-FKN. ${ }^{*} \mathrm{P}<0.05$, vs. normoxia; ${ }^{\#} \mathrm{P}<0.05$, vs. normoxia +200 pg/ml rFKN + IgG. Data are expressed as the mean \pm standard error of the mean. FKN, fractalkine; aFKN, anti-FKN; rFKN, human recombinant FKN protein; OD, optical density.

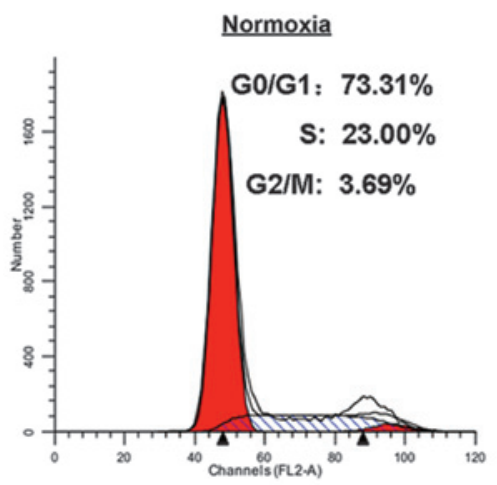

C

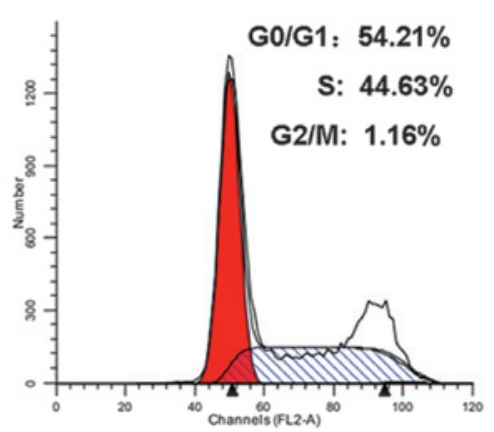

B

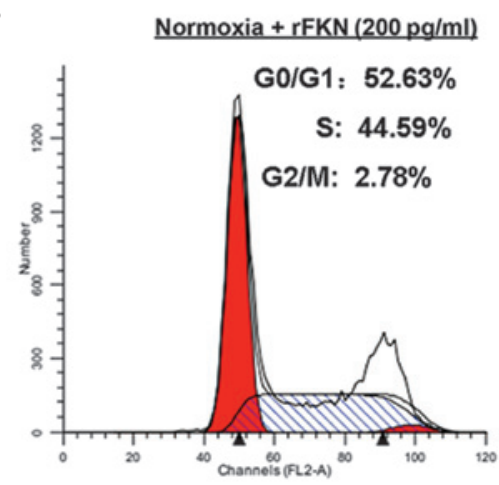

D

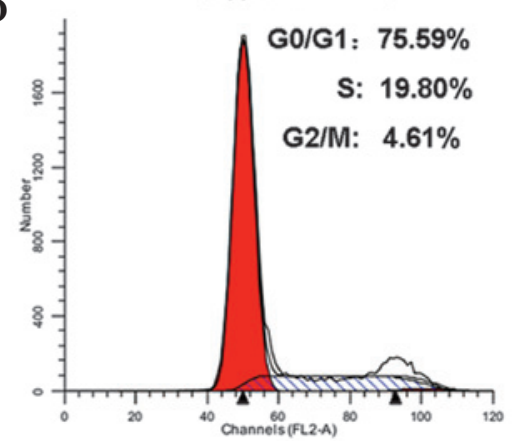

Figure 5. Effect of FKN on the cell cycle regulation in DU145 cells. Cell cycle distribution was determined using flow cytometry. (A and B) exogenous FKN protein decreased the proportion of cells in G1 phase from 73.31 to $52.63 \%$, and increased the proportion of cells in S phase from 23.00 to $44.59 \%$. (C and D) hypoxic treatment decreased the proportion of cells in G1 phase from 73.31 to $54.21 \%$, and increased the proportion of cells in S phase from 23.00 to $44.63 \%$. However, anti-FKN pre-treatment increased the proportion of cells in G1 phase from 54.21 to $75.59 \%$ and decreased the S-phase population from 44.63 to $19.80 \%$. FKN, fractalkine; aFKN, anti-FKN; rFKN, human recombinant FKN protein.

FKN promotes $G_{l} / S$ phase transition by upregulating the expression levels of cyclin $E$ and $C D K 2$. Cell proliferation is closely associated with cell cycle regulation. In order to determine whether hypoxia-induced prostate cancer cell proliferation was associated with cell cycle regulation by FKN, the cell cycle distribution in the DU145 cells was measured under normoxic or hypoxic conditions using flow cytometric analysis (Fig. 5). Compared with normoxic conditions (Fig. 5A and B), hypoxic treatment decreased the proportion of cells in the $G_{1}$ phase, between 73.31 and $54.21 \%$, and increased the proportion of cells in the S phase, between 23.00 and 44.63\%. However, anti-FKN pre-treatment increased the proportion of cells in the $\mathrm{G}_{1}$ phase between 54.21 and $75.59 \%$. and decreased the proportion in the $\mathrm{S}$ phase, between 44.63 and $19.80 \%$, which suggested that antagonizing FKN inhibited the $G_{1}$ to $S$ phase transition induced by hypoxia (Fig. 5C and D). To further elucidate the role of FKN in cell cycle regulation, the cell cycle distribution of DU145 cells pre-incubated with $200 \mathrm{pg} / \mathrm{ml}$ 
A
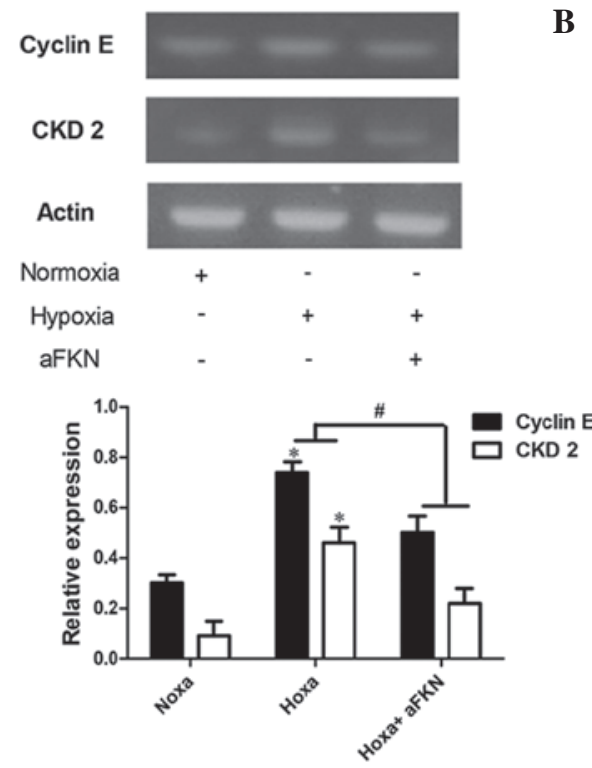

C

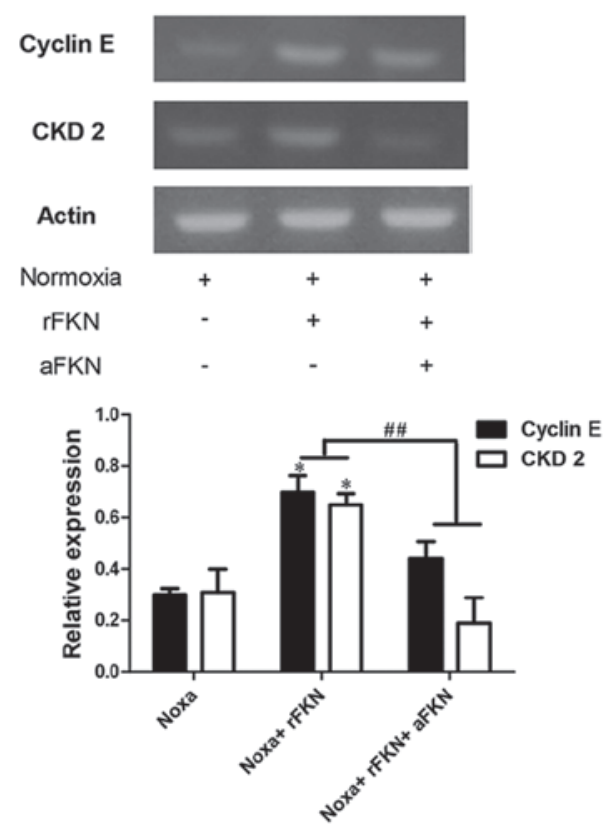

B

D
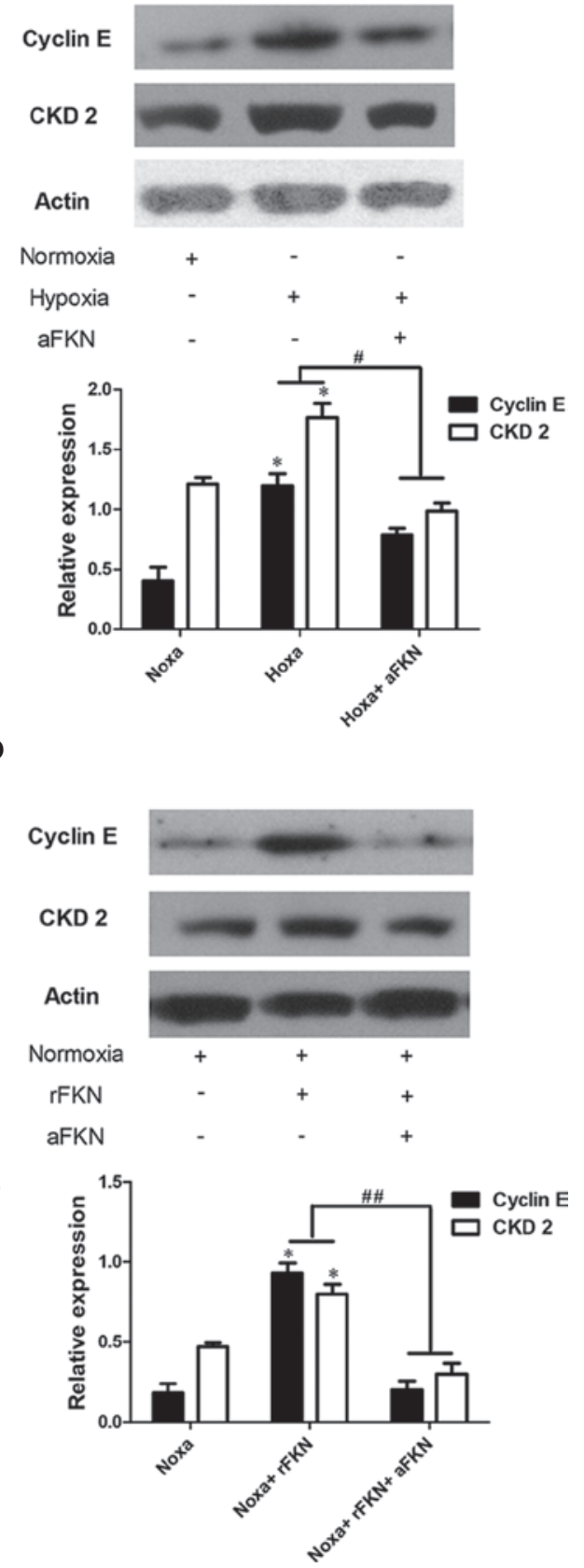

Figure 6. Effects of FKN on the mRNA and protein expression of cyclinE and CDK2 in DU145 cells. (A and B) Reverse transcription-quantitative polymerase chain reaction. (C and $\mathrm{D}$ ) western blot analysis. $\beta$-actin was used as a loading control. ${ }^{*} \mathrm{P}<0.05$, vs. Noxa; ${ }^{\#} \mathrm{P}<0.05$, vs. Hoxa; ${ }^{\# \#} \mathrm{P}<0.05$, vs. Noxa+rFKN. Data are expressed as the mean \pm standard error of the mean. CDK, cyclin-dependent kinase; aFKN, anti-FKN; rFKN, human recombinant FKN protein; Noxa, normoxia; Hoxa, hypoxia.

human recombinant FKN protein under normoxic conditions was analyzed. As shown in Fig. 5A and B, exogenous FKN protein administration decreased the proportion of cells in the $\mathrm{G}_{1}$ phase between 73.31 to $52.63 \%$, and increased the proportion of cells in the $\mathrm{S}$ phase between 23.00 and $44.59 \%$. These results suggested that $F K N$ promoted the $G_{1} / S$ phase cell cycle transition.

Cell cycle progression depends on the formation of $\mathrm{CDK} /$ cyclin complexes, and cyclin $\mathrm{E}$ and CDK2 are $\mathrm{G}_{1} / \mathrm{S}$ phase-specific regulators (20). Therefore, the present study determined the mRNA and protein expression levels of cyclin E and CDK2 using RT-qPCR and western blot analysis. As shown in Fig. 6A-D, the mRNA and protein expression levels of cyclin E and CDK2 in the DU145 cells exposed to hypoxia were significantly higher than those in the cells exposed to normoxic conditions $(\mathrm{P}<0.05)$, and anti-FKN pre-treatment markedly attenuated the increased expression levels of cyclin $\mathrm{E}$ and $\mathrm{CDK} 2(\mathrm{P}<0.05)$. To further verify the role of FKN in the regulation of cyclin $\mathrm{E}$ and CDK2, the expression levels of cyclin E and CDK2 in DU145 cells exposed to normoxia with anti-FKN or exogenous FKN protein pre-treatment were also examined. The mRNA and protein expression levels of cyclin E and CDK2 were significantly elevated by $200 \mathrm{pg} / \mathrm{ml}$ exogenous FKN protein administration $(\mathrm{P}<0.05)$, and anti-FKN pretreatment markedly alleviated this increase $(\mathrm{P}<0.05$; Fig. $6 \mathrm{C}$ and $\mathrm{D})$. 


\section{Discussion}

Prostate cancer is the most frequently diagnosed type of malignancy and is the second leading cause of cancer-associated mortality in males (21). Early-stage prostate cancer depends on androgens for growth and survival, and androgen ablation therapy causes them to regress (22). However, cancer, which is not cured by surgical procedures eventually become androgen-independent, and androgen ablation fails to target androgen-independent cells (23). Therefore, examining the underlying molecular mechanisms and potential therapeutic targets in androgen-independent prostate cancer is essential for improving clinical outcomes. The present study presented data, which demonstrated that hypoxia, a common phenomenon in prostate cancer, induced the expression and secretion of FKN, and that antagonizing FKN inhibited hypoxic prostate cancer cell proliferation.

A hypoxic microenvironment contributes to the progression of cancer (19). Under certain conditions, the interaction between tumor cells and their microenvironment is facilitated by a variety of soluble factors, including growth factors and chemokines (24). Hypoxia has been suggested to promote cell migration and invasion in various types of tumor by regulating specific chemokine receptors (25-27). FKN is the only member recognized so far, which belongs to the $\mathrm{CX} 3 \mathrm{C}$ chemokine subfamily. FKN exists as a membrane-bound form functioning as an adhesion molecule, and as a soluble form acting as a potent chemoattractant for monocytes, natural killer cells and T cells (28). Therefore, FKN is important in several disorders comprising imbalance of the immune response, including arthritis (29), asthma (30), human immunodeficiency virus (31) and Crohn's disease (32). In addition, the involvement of FKN/CX3CR1 in the pathogenesis and progression of multiple malignant diseases has also been a focus of interest. For certain tumor entities, FKN was demonstrated to be correlated with a higher local recurrence risk and metastatic potential $(33,34)$. In epithelial ovarian cancer cells, FKN functions as an important regulator of malignant cell proliferation via binding to CX3CR1 and consequently activating AKT signaling (35). In prostate cancer, neutralizing antibodies against FKN markedly repress the ability of prostate cancer cells to adhere to the bone marrow endothelium (15). In the present study, the results demonstrated that hypoxia promoted cell proliferation in two types of androgen-independent prostate cancer cell lines, DU145 and PC-3. Subsequently, the effects of hypoxia on FKN synthesis and secretion were investigated in the prostate cancer cells. The results demonstrated that hypoxia induced the secretion and mRNA expression of FKN in a sustained manner. Based on these observations, it was hypothesized that FKN was associated with prostate cancer cell proliferation. The present study subsequently determined DU145 cell proliferation rates following FKN inhibition with the anti-FKN FKN-specific antibody under hypoxic conditions. The results demonstrated that anti-FKN pre-treatment markedly inhibited DU145 cell proliferation. To further investigate the role of FKN under normoxic conditions, DU145 cell proliferation was examined following the administration of exogenous human recombinant FKN protein. The results revealed that DU145 cell proliferation markedly increased, and this increase was significantly alleviated by treatment with anti-FKN, which indicated that DU145 cell proliferation was mediated by FKN. These data suggested that upregulation of the expression and secretion of FKN was involved in hypoxia-induced prostate cancer cell proliferation.

Cellular proliferation follows an orderly progression through the cell cycle. The traditional subdivisons of the standard cell cycle include the $\mathrm{G}_{1}, \mathrm{~S}, \mathrm{G}_{2}$ and $\mathrm{M}$ phases (36). Accumulating evidence has suggested the relevance of cell cycle deregulation in human cancer. The majority of types of human cancer exhibit deregulated control of $\mathrm{G}_{1}$ phase progression, a period during which the cells either initiate proliferation or remain quiescent (37). The present study examined the role of FKN in prostate cancer cell cycle regulation using flow cytometry, and the results revealed that either exogenous FKN protein administration or hypoxic treatment notably increased the proportion of cells in the S phase, and anti-FKN pre-treatment attenuated hypoxia-induced cell accumulation in the $\mathrm{S}$ phase. These data indicated that FKN regulated the $\mathrm{G}_{1} / \mathrm{S}$ checkpoint, resulting in promotion of the $\mathrm{G}_{1}$ to $S$ phase transition. The transition between one cycle phase and another occurs in order and is regulated by a variety of cell cycle regulators, the most prominent of which are cyclins and their associated CDKs. Of these, cyclin E is important for initiation of the $\mathrm{S}$ phase, and its association with CDK2 regulates the progression between the $\mathrm{G}_{1}$ and $\mathrm{S}$ phase (38). The results of the present study demonstrated that antagonizing FKN attenuated the hypoxia-induced mRNA and protein expression levels of cyclin $\mathrm{E}$ and $\mathrm{CDK} 2$ in the prostate cancer cells. By contrast, prostate cancer cells, exposed to exogenous FKN protein pre-treatment under normoxic conditions exhibited elevated mRNA and protein expression levels of cyclin E and CDK2, and anti-FKN pre-treatment markedly alleviated this elevation. These findings suggested that $F K N$ promoted $\mathrm{G}_{1} / \mathrm{S}$ cell cycle progression through upregulating the expression levels of cyclin E and CDK2, resulting in hypoxic prostate cancer cell proliferation.

Aberrant epidermal growth factor receptor (EGFR) signaling is associated with characteristics of aggressive malignancies, including increased proliferative potential, nitric oxide synthesis and accelerated $\mathrm{G}_{1} / \mathrm{S}$ cell cycle progression. White et al (39) reported that EGFR activation is involved in the proliferation of human vascular smooth muscle cells in response to FKN treatment. Therefore, hypoxia may induce the secretion of FKN and subsequent EGFR signaling activation, which promotes cell cycle progression, resulting in increased cell proliferation.

In conclusion, the results of the present study provided evidence of a novel function for FKN, which enhances cell proliferation by promoting cell cycle progression in hypoxic prostate cancer cells. Further investigations are required to further expand on these findings, with the goal of identifying a potential therapeutic target.

\section{Acknowledgements}

This study was supported by grants from the National Natural Science Foundation of China (no. 30973010), the Natural Science Foundation of Heilongjiang Province of China (no. QC2009C115) and the startup Fund of The Affiliated Third Hospital of Harbin Medical University (no. JJ2011-12). 


\section{References}

1. Siegel R, Ma J, Zou Z and Jemal A: Cancer statistics, 2014. CA Cancer J Clin 64: 9-29, 2014

2. Baade PD, Youlden DR, Cramb SM, Dunn J and Gardiner RA: Epidemiology of prostate cancer in the Asia-Pacific region. Prostate Int 1:47-58, 2013.

3. Freedland SJ: Screening, risk assessment and the approach to therapy in patients with prostate cancer. Cancer 117: 1123-1135, 2011.

4. Taiakina D, Dal Pra A and Bristow RG: Intratumoral hypoxia as the genesis of genetic instability and clinical prognosis in prostate cancer. Adv Exp Med Biol 772: 189-204, 2014.

5. Voss MJ, Niggemann B, Zänker KS and Entschladen F: Tumour reactions to hypoxia. Curr Mol Med 10: 381-386, 2010.

6. Jones BA, Beamer M and Ahmed S: Fractalkine/CX3CL1: A potential new target for inflammatory diseases. Mol Interv 10: 263-270, 2010.

7. Lucas AD, Bursill C, Guzik TJ, Sadowski J, Channon KM and Greaves DR: Smooth muscle cells in human atherosclerotic plaques express the fractalkine receptor CX3CR1 and undergo chemotaxis to the CX3C chemokine fractalkine (CX3CL1). Circulation 108: 2498-2504, 2003.

8. Blaschke S, Koziolek M, Schwarz A, Benöhr P, Middel P, Schwarz G, Hummel KM and Müller GA: Proinflammatory role of fractalkine (CX3CL1) in rheumatoid arthritis. J Rheumatol 30: 1918-1927, 2003

9. Tang L, Hu HD, Hu P, Lan YH, Peng ML, Chen M and Ren H: Gene therapy with CX3CL1/Fractalkine induces antitumor immunity to regress effectively mouse hepatocellular carcinoma. Gene Ther 14: 1226-1234, 2007.

10. Faure S, Meyer L, Costagliola D, Vaneensberghe C, Genin E, Autran B, Delfraissy JF, McDermott DH, Murphy PM, Debré $\mathrm{P}$, et al: Rapid progression to AIDS in HIV+ individuals with a structural variant of the chemokine receptor CX3CR1. Science 287: 2274-2277, 2000.

11. Ludwig A, Hundhausen C, Lambert MH, Broadway N, Andrews RC, Bickett DM, Leesnitzer MA and Becherer JD: Metalloproteinase inhibitors for the disintegrin-like metalloproteinases ADAM10 and ADAM17 that differentially block constitutive and phorbol ester-inducible shedding of cell surface molecules. Comb Chem High Throughput Screen 8: 161-171, 2005.

12. Jamieson WL, Shimizu S, D'Ambrosio JA, Meucci O and Fatatis A: CX3CR1 is expressed by prostate epithelial cells and androgens regulate the levels of CX3CL1/fractalkine in the bone marrow: Potential role in prostate cancer bone tropism. Cancer Res 68: 1715-1722, 2008.

13. Nevo I, Sagi-Assif O, Meshel T, Ben-Baruch A, Jöhrer K, Greil R, Trejo LE, Kharenko O, Feinmesser M, Yron I and Witz IP: The involvement of the fractalkine receptor in the transmigration of neuroblastoma cells through bone-marrow endothelial cells. Cancer Lett 273: 127-139, 2009.

14. Erreni M, Solinas G, Brescia P, Osti D, Zunino F, Colombo P, Destro A, Roncalli M, Mantovani A, Draghi R, et al: Human glioblastoma tumours and neural cancer stem cells express the chemokine CX3CL1 and its receptor CX3CR1. Eur J Cancer 46: 3383-3392, 2010.

15. Shulby SA, Dolloff NG, Stearns ME, Meucci O and Fatatis A: CX3CR1-fractalkine expression regulates cellular mechanisms involved in adhesion, migration and survival of human prostate cancer cells. Cancer Res 64: 4693-4698, 2004.

16. Lu Y, Cai Z, Galson DL, Xiao G, Liu Y, George DE, Melhem MF, Yao Z and Zhang J: Monocyte chemotactic protein-1 (MCP-1) acts as a paracrine and autocrine factor for prostate cancer growth and invasion. Prostate 66: 1311-1318, 2006.

17. Xiao LJ, Chen YY, Lin P, Zou HF, Lin F, Zhao LN, Li D, Guo L, Tang JB, Zheng XL and Yu XG: Hypoxia increases CX3CR1 expression via HIF-1 and NFKB in androgen-independent prostate cancer cells. Int J Oncol 41: 1827-1836, 2012.

18. Xiao LJ, Lin P, Lin F, Liu X, Qin W, Zou HF, Guo L, Liu W, Wang SJ and Yu XG: ADAM17 targets MMP-2 and MMP-9 via EGFR-MEK-ERK pathway activation to promote prostate cancer cell invasion. Int J Oncol 40: 1714-1724, 2012.

19. Hasegawa M, Sato S, Echigo T, Hamaguchi Y, Yasui M and Takehara K: Up regulated expression of fractalkine/CX3CL1 and CX3CR1 in patients with systemic sclerosis. Ann Rheum Dis 64: 21-28, 2005.
20. Harbour JW, Luo RX, Dei Santi A, Postigo AA and Dean DC: Cdk phosphorylation triggers sequential intramolecular interactions that progressively block $\mathrm{Rb}$ functions as cells move through G1. Cell 98: 859-869, 1999.

21. Ferlay J, Shin HR, Bray F, Forman D, Mathers C and Parkin DM: Estimates of worldwide burden of cancer in 2008: GLOBOCAN 2008. Int J Cancer 127: 2893-2917, 2010.

22. Nishimura S, Hato M, Hyugaji S, Feng $F$ and Amano M: Glycomics for drug discovery: Metabolic perturbation in androgen-independent prostate cancer cells induced by unnatural hexosamine mimics. Angew Chem Int Ed Engl 51: 3386-3390, 2012.

23. Feldman BJ and Feldman D: The development of androgen-independent prostate cancer. Nat Rev Cancer 1: 34-45, 2001.

24. Borsig L, Wolf MJ, Roblek M, Lorentzen A and Heikenwalder M: Inflammatory chemokines and metastasis-tracing the accessory. Oncogene 33: 3217-3224, 2013.

25. Waugh DJ, Wilson C, Seaton A and Maxwell PJ: Multi-faceted roles for CXC-chemokines in prostate cancer progression. Front Biosci 13: 4595-4604, 2008.

26. Zhang S, Qi L, Li M, Zhang D, Xu S, Wang N and Sun B: Chemokine CXCL12 and its receptor CXCR4 expression are associated with perineural invasion of prostate cancer. J Exp Clin Cancer Res 27: 62, 2008.

27. Wang J, Lu Y, Wang J, Koch AE, Zhang J and Taichman RS: CXCR6 induces prostate cancer progression by the AKT/mammalian target of rapamycin signaling pathway. Cancer Res 68: 10367-10376, 2008.

28. Bazan JF, Bacon KB, Hardiman G, Wang W, Soo K, Rossi D, Greaves DR, Zlotnik A and Schall T: A new class of membrane-bound chemokine with a CX3C motif. Nature 385: 640-644, 1997.

29. Koch AE: Chemokines and their receptors in rheumatoid arthritis: Future targets? Arthritis Rheum 52: 710-721, 2005.

30. Rimaniol AC, Till SJ, Garcia G, Capel F, Godot V, Balabanian K, Durand-Gasselin I, Varga EM, Simonneau G, Emilie D, et al: The CX3C chemokine fractalkine in allergic asthma and rhinitis. J Allergy Clin Immunol 112: 1139-1146, 2003.

31. Foussat A, Bouchet-Delbos L, Berrebi D, Durand-Gasselin I, Coulomb-L'Hermine A, Krzysiek R, Galanaud P, Levy Y and Emilie D: Deregulation of the expression of the fractalkine/fractalkine receptor complex in HIV-1-infected patients. Blood 98: 1678-1686, 2001.

32. Muehlhoefer A,SaubermannLJ,GuX,Luedtke-HeckenkampK, Xavier R, Blumberg RS, Podolsky DK, MacDermott RP and Reinecker HC: Fractalkine is an epithelial and endothelial cell-derived chemoattractant for intraepithelial lymphocytes in the small intestinal mucosa. J Immunol 164: 3368-3376, 2000.

33. Blum DL, Koyama T, M'Koma AE, Iturregui JM, Martinez-Ferrer M, Uwamariya C, Smith JA Jr, Clark PE and Bhowmick NA: Chemokine markers predict biochemical recurrence of prostate cancer following prostatectomy. Clin Cancer Res 14: 7790-7797, 2008.

34. Xu X, Wang Y, Chen J, Ma H, Shao Z, Chen H and Jin G: High expression of CX3CL1/CX3CR1 axis predicts a poor prognosis of pancreatic ductal adenocarcinoma. J Gastrointest Surg 16: 1493-1498, 2012.

35. Gaudin F, Nasreddine S, Donnadieu AC,Emilie D, Combadière C, Prévot S, Machelon V and Balabanian K: Identification of the chemokine CX3CL1 as a new regulator of malignant cell proliferation in epithelial ovarian cancer. PloS one 6: e21546, 2011.

36. Vermeulen K, Van Bockstaele DR and Berneman ZN: The cell cycle: A review of regulation, deregulation and therapeutic targets in cancer. Cell Prolif 36: 131-149, 2003.

37. Malumbres $\mathrm{M}$ and Carnero A: Cell cycle deregulation: A common motif in cancer. Prog Cell Cycle Res 5: 5-18, 2003.

38. Golias $\mathrm{CH}$, Charalabopoulos A and Charalabopoulos K: Cell proliferation and cell cycle control: A mini review. Int J Clin Pract 58: 1134-1141, 2004.

39. White GE, Tan TC, John AE, Whatling C, McPheat WL and Greaves DR: Fractalkine has anti-apoptotic and proliferative effects on human vascular smooth muscle cells via epidermal growth factor receptor signalling. Cardiovasc Res 85: 825-835, 2010 . 